\title{
DESMISTIFICANDO A ARTE DO NOSSO TEMPO PARA O ENSINO MÉDIO
}

\author{
Júnia de Barros Braga Vasconcelos ${ }^{1}$
}

ESCOLA DE APLICAÇÃO/UFPA

\begin{abstract}
RESUMO:
Apresento, neste trabalho, a experiência realizada no ano letivo de $2006 \mathrm{com}$ alunos do $1^{0}$ ano do Ensino Médio da Escola de Aplicação da UFPA (Núcleo Pedagógico Integrado), tendo como temática a Arte Contemporânea, com o objetivo de levá-los a compreender seu papel peculiar entre as outras imagens do nosso cotidiano. Para isso, foi realizado um trabalho de embasamento teórico para que eles fossem capazes de apreciar e produzir esta arte de nosso tempo, que não é tão compreendida pela maioria das pessoas. Apresentamos ainda a exposição, realizada pelos alunos, das obras produzidas por eles como culminância da etapa prática deste processo. Trabalhar a arte contemporânea é pensar a história viva, é tocar em feridas abertas, levando os alunos a uma reflexão de uma realidade em que ele está inserido e é participante ativo, e de qual seria seu papel social diante de determinada problemática.
\end{abstract}

PALAVRAS-CHAVE: ensinando - arte contemporânea

\section{RÉSUMÉ:}

Je présente dans ce résumé les résultats d'une expérience réalisée pendant l'année scolaire 2006 avec les élèves de première année du Lycée de l'École d'Application de I'UFPa (Nucleo Pedagogico Integrado) sur le sujet "Art Contemporain". L'objectif de l'expérience est de faire prendre conscience aux élèves de leur rôle parmi les images de la vie quotidienne. Un travail théorique fut réalisé auparavant pour permettre aux élèves d'apprécier et de produire l'art contemporain, incompris par la plupart des gens. La partie pratique du projet est aussi présentée à travers une exposition des oeuvres réalisées par les élèves. L'étude de l'art contemporain invite à la réflexion sur l'histoire vivante et sur les blessures de la société. Elle amène les élèves à penser sur la réalité dans laquelle ils sont participants actifs et sur leur rôle social devant des problématiques bien déterminées.

Мот CLE: enseignement - art contemporain

\section{INTRODUÇÃO}

Sou professora de Arte há onze anos e constantemente me questionam em relação aos objetos "estranhos", que encontramos hoje em dia em livros e exposições, que são considerados como obra de arte. Algumas das perguntas e comentários frequentes são: mas isso é arte? Até eu ou meu irmão de dois anos faria isso. Se eu fizer a mesma coisa com um objeto que tem lá em casa, posso ficar famoso também? Por mais estranha e banal que possa parecer, a arte 
e-Mosaicos - Revista Multidisciplinar de Ensino, Pesquisa, Extensão e Cultura do Instituto de Aplicação Fernando Rodrigues da Silveira (CAp-UERJ) ANO 1 - V. 1 - N. 1 - JUNHO 2012 - ISSN: 2316-9303

dos nossos tempos é fruto da própria sociedade, pois dialoga com ela através de uma linguagem ampla, imbuída de uma crítica reveladora de seus problemas mais ontológicos. Na prática, por mais bonita e elaborada que fosse minha resposta, algumas vezes em que ministrei arte contemporânea, percebi que ela não convencia meus alunos como uma linguagem autêntica e profunda.

A maioria das pessoas que dizem que não gostam da arte contemporânea, na verdade, não a compreendem, pois ela não é óbvia nem narrativa. Não é a toa que este estranhamento acontece não só por parte dos alunos, mas também dos adultos em geral, pois somos frutos de uma cultura tradicional que já absorveu o padrão acadêmico de arte como sendo o certo, o belo: aquele que busca a mimeses da natureza, ou seja, a utilização de técnicas que produzam a sua imitação da maneira mais perfeita possível.

Nas ciências em geral, sempre foi mais fácil aceitar aquilo que já está consagrado como verdade, do que compreender algo que não encontra referência dentro de si. Para THITLEWOOD (1997),

a arte contemporânea deveria prestar-se a uma eventual explicação textual (fez isso no passado), mas as primeiras relações serão especulativas, tentativas, muitas vezes incorretas e não convincentes. Existe um período necessário até que a arte contemporânea se torne inteligível para o público em geral: os Monets, indecifráveis em sua época, estão agora em todas as salas de visita. Aquilo que não pode ser transmitido em palavras, entretanto, pode ser aprendido em um dialogo vivo, e a maneira mais produtiva de identificar a arte contemporânea é exercitar o julgamento, a desconstrução e a resposta criativa. (THISTLEWOOD, 1997, p. 147)

Possivelmente as próximas gerações oIharão a arte de nosso tempo com menos preconceitos que nós, mas isso não nos exime da necessidade de buscar sua compreensão, o que, segundo o autor citado, se dá através de uma observação atenta, sem padrões pré-estabelecidos, e do julgamento sem medo de erros e sem querer achar verdades, e sim possibilidades.

Incumbindo-me desta responsabilidade não só de estudar com os alunos, mas de vivenciar coletivamente e de forma significativa a arte dos nossos tempos, apresento, neste trabalho, a experiência realizada no ano letivo de $2006 \mathrm{com}$ alunos do $1^{\circ}$ ano do Ensino Médio da Escola de Aplicação da UFPA.

O objetivo deste trabalho, em primeiro lugar, foi levar os alunos a compreenderem a arte, de forma geral, como manifestação humana que envolve produção, conhecimento e expressão, entendendo em particular a construção da Arte Contemporânea, percebendo as questões sócio-históricas que contribuíram para a mudança dos padrões tradicionais de beleza e para a criação de novas categorias de linguagens artísticas. A partir disso, levá-los a perceber a si mesmos como seres capazes de compreender as diversas realidades de seu cotidiano e expressá-las de forma crítica, através de linguagens artísticas contemporâneas.

Este trabalho foi desenvolvido, juntamente com os alunos, em duas etapas: a primeira de cunho teórico-reflexivo, e a segunda de cunho prático. No primeiro mo- 
e-Mosaicos - Revista Multidisciplinar de Ensino, Pesquisa, Extensão e Cultura do Instituto de Aplicação Fernando Rodrigues da Silveira (CAp-UERJ)

ANO 1 - V. 1 - N. 1 - JUNHO 2012 - ISSN: 2316-9303

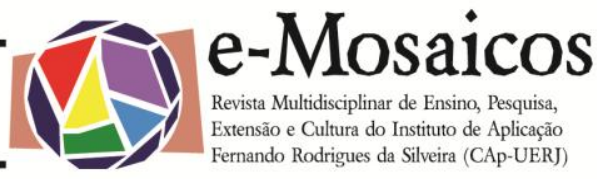

mento apresentaremos como se desenvolveu o trabalho de fundamentação básica, a partir dos seguintes conteúdos: o conceito de belo, a construção da arte contemporânea, suas características e categorias de linguagem. Aqui analisaremos como esses elementos possibilitaram os alunos a conceituar e identificar obras contemporâneas. No segundo momento, apresentaremos o processo de criação artística pelo qual os alunos passaram, começando com a elaboração de um projeto e culminando com a exposição dos trabalhos desenvolvidos.

\section{ARTE CONTEMPORÂNEA: QUE BICHO É ESSE?}

Arte é beleza, com certeza! Este é o conceito comum que se tem para arte, afinal, o próprio ramo da filosofia que a estuda é a Estética, conhecida como a ciência do belo. $O$ grande problema é saber qual o referencial que se tem para julgar a arte como bela. Este foi o primeiro problema encontrado em sala de aula, uma vez que os alunos jamais compreenderiam a arte contemporânea, tendo como referência o tradicional conceito de beleza. Como as transformações nos parâmetros do Belo, ao longo da história, confundem-se com a construção da própria arte contemporânea, estes dois primeiros conceitos foram trabaIhados em conjunto, através de filmes e aulas expositivas e dialogadas, a partir da leitura de imagens.

Segundo COSTA (1999, p.25), a ideia de beleza como algo alegre, agradável e saudável advém da Antiguidade Clássica, pois "a arte que lá se fazia pretendia expressar um ideal de beleza e vida através de composições nas quais predominassem a harmonia, a simetria, o equilíbrio e a proporcionalidade." Por causa dos seus critérios e princípios, esta arte foi considerada um modelo e inspirou vários movimentos artísticos da idade moderna, como o renascimento e o classicismo.

No Renascimento, se constrói um sistema espacial de representação pictórica, onde, no intuito de representar a visualidade do real de forma ideal dentro da bidimensionalidade, enquadram o mundo dentro de um ilusionismo cúbico, construído pela representação perspectiva do espaço, que promove a sensação de aprofundamento, e por um sistema de modulação volumétrica, através do uso da luz e sombra. Essa forma de representação não é apenas fruto de um saber técnico, mas advém das crenças e concepções individuais e coletivas da época. O sistema renascentista perdurou durante quatro séculos, sofrendo alguns acréscimos e eliminações, mas sem que seus fundamentos fossem modificados. Assim, este tipo de arte foi disseminado pelo mundo, e o conceito de Belo, atrelado à aparente imitação da natureza e às manifestações artísticas agradáveis e harmoniosas, predominou como o desejável e aceitável.

Num estudo das relações entre arte e sociedade, FRANCASTEL afirma em seu livro Pintura e Sociedade que as mudanças de uma forma de representação plástica, ao longo da história, estão relacionadas ao nascimento e declínio dos valores de uma civilização. Segundo ele:

Pode-se perfeitamente imaginar a possibilidade de ver modificarse o modo de representação do espaço em função de uma transformação profunda dos conhecimentos técnicos ou teóricos, ao mesmo tempo que das crenças e dos móveis de ação de uma sociedade. (FRANCASTEL, 1990, p.110) 
e-Mosaicos - Revista Multidisciplinar de Ensino, Pesquisa, Extensão e Cultura do Instituto de Aplicação Fernando Rodrigues da Silveira (CAp-UERJ) ANO 1 - V. 1 - N. 1 - JUNHO 2012 - ISSN: 2316-9303

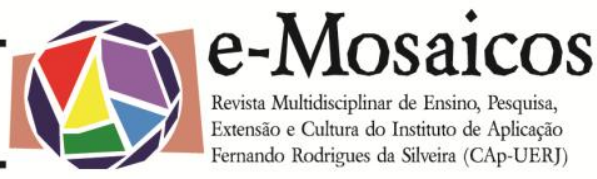

Se essas modificações do modo de representação são frutos das transformações sociais, haveriam de se mudar também os parâmetros de Belo. Porém, mesmo sendo a arte fruto do pensamento de uma época e de um contexto social, nem sempre a sociedade está apta para entender sua própria realidade, daí nem sempre a arte contemporânea agradar, no seu próprio tempo.

Um artista era avaliado não só por seu poder de criação, mas também pelos critérios da maestria artesanal. No século XIX, com a possibilidade da fotografia representar fielmente o que se vê, e com a produção em série, proporcionada pela Revolução Industrial, os artistas são levados a buscarem outras formas de expressão.

No Impressionismo, apesar do registro das sensações luminosas e da representação dos objetos e do espaço pela cor, eles não chegam a subverter o sistema figurativo do Renascimento, pois, por trás de sua composição manchada e repleta de pequenas pinceladas, ainda podemos encontrar a tradicional grade perspectiva. Mesmo sem muitas mudanças, a configuração das obras dos impressionistas não foi aceita na sua época, levando-os a expor no Salão dos Independentes.

A necessidade de a pintura relacionarse com o mundo exterior vai sendo, aos poucos, desconstruída através da pesquisa pessoal dos pós-impressionistas Cézanne, Dégas, Gauguim e Van Gogh, o que reflete na arbitrariedade das cores, na deformação das figuras e na quebra de leis físicas e artísticas (gravidade e perspectiva), dando autonomia espacial e plástica à pintura. Com a preparação deste caminho, no século XX se operará a construção de um novo sistema pictórico de novas relações espaciais, sobre o qual serão construídos os vários movimentos artísticos.
Destacamos dois artistas modernos das primeiras décadas do século XX que sintetizaram em si atitudes inovadoras, até mesmo radicais, tidas em seu tempo como pura loucura ou subversão, mas que, a partir da década de 1960, foram sementes frutíferas para as transformações que se haveriam de executar na arte contemporânea: Pablo Picasso e Marcel Duchamp.

Na sua experiência com o Cubismo, Picasso elabora uma forma de representação que ficaria marcada em quase toda sua promissora produção. Os rostos, que muitas vezes parecem grosseiros por apresentarem olhos desalinhados, nariz no lugar de uma das orelhas e boca desfigurada, a exemplo da obra "Guernica" (Fig. 01), não são apenas efeitos de seu desejo de deformação. $\mathrm{Na}$ verdade, ele introduz um conceito científico de quarta dimensão (as três dimensões tradicionais utilizadas nas artes visuais são altura, largura e profundidade; o tempo é a quarta dimensão, conceito utilizado na físi$\mathrm{ca}$ ), onde a aparente deformação resultaria dos vários pontos de vista de uma pessoa, representados no mesmo momento. $\mathrm{O}$ tempo seria então um complexo conceito que está presente na arte contemporânea.

A introdução de elementos do cotidiano nas obras de arte aparecem, primeiramente, com as assemblagens de Picasso, através da colagem de pedaços de jornais, papéis e tecidos nas telas, mas são radicalmente utilizadas com os ready made de Marcel Duchamp. Em sua obra dadaísta $A$ Fonte, ele apropria-se de um urinol de porcelana branco, objeto manufaturado anônimo que fora escolhido "desinteressadamente", e, com os simples gestos de invertê-lo e assiná-lo, o converte em obra de arte. Com esta atitude, Duchamp contribui duplamente para a arte contemporânea, com a utilização de objetos do cotidiano e com a atribuição 
e-Mosaicos - Revista Multidisciplinar de Ensino, Pesquisa, Extensão e Cultura do Instituto de Aplicação Fernando Rodrigues da Silveira (CAp-UERJ) ANO 1 - V. 1 - N. 1 - JUNHO 2012 - ISSN: 2316-9303

de um conceito a ele, contestando, assim, a sacralidade da obra de arte e discutindo as próprias bases da concepção artística.

A postura crítica e criativa dos dadaístas na intenção de subverter a arte tradicional e institucionalizada não só permitiu o uso de novos materiais, mas revitalizou o tradicional modo de fazer pintura, escultura e gravura, possibilitando a criação de outras linguagens artísticas: a colagem (ou fotomontagem) e o objeto.

Na segunda metade do Século XX, os objetos do cotidiano estiveram cada vez mais presentes na construção da obra de arte, sobretudo em um movimento chamado Conceitual, pois ele atribuía a estes objetos um conceito que precisava ser desvendado pelo observador. Este movimento tem suas raízes na postura dadaísta, e é conhecido também por Arte como Ideia, porque a ideia da obra foi posta como superior ao próprio objeto.

Se na arte tradicional a beleza estava atrelada à capacidade da obra em representar o mundo visível o mais perfeito possível, segundo BARCO (2005), na Arte Conceitual, e na Arte Contemporânea, de modo geral, "o impacto pelo belo foi substituído pelo estranhamento", o que instiga a participação do observador, que não pode mais ficar passivo diante da obra, mas é convidado a pensar.

A obra de arte contemporânea, então, só está completa quando ele consegue solucionar o seu enigma. Para BARCO (2005), "ao espectador cabe agora não apenas o deslumbramento diante de uma pintura ou escultura, ele deve desvendar o que aquelas obras significam, penetrar nos sentidos e ideias sintetizadas pela experiência do artista," e nisso encontra-se sua verdadeira beleza.
As transformações do mundo pósmoderno e as mudanças conceituais da arte proporcionaram a construção da arte contemporânea, essa arte de nossos tempos, que os artistas estão produzindo e estão sendo expostas, não apenas em nossos museus, mas nas ruas, prédios públicos e meios de comunicação, como a internet.

Esta arte tem suas peculiaridades e, para que os alunos pudessem entendê-la em sua totalidade, trabalhamos as características que nos permitem identificá-la: o conceito, as novas categorias de linguagens artísticas, a participação do espectador, o tempo e as novas tecnologias.

O conceito é a ideia da qual o artista concebe e produz a obra. Partimos do pressuposto de que toda a obra contemporânea traz um olhar crítico a respeito do mundo, seja sob uma ótica social, ambientalista, política, existencialista ou mesmo a respeito dos próprios conteúdos e conceitos de arte. Esta intenção do artista está inserida diretamente na obra, influenciando a configuração plástica da mesma. Ao espectador cabe agora não apenas o deslumbramento diante de uma obra. Ele deve desvendar o que elas significam, penetrando nos sentidos e nas ideias que foram sintetizadas pelo artista.

A introdução dos objetos cotidianos e a quebra dos paradigmas da arte tradicional abrem espaço para que se façam experiências com novas categorias de linguagens artísticas que surgem do hibridismo das tradicionais categorias de desenho, pintura e escultura. Estas novas linguagens adentram por espaços antes impossíveis, mas que agora configuram a arte como ambiental (a instalação, a land art e a intervenção), envolvem a linguagem cênica (a body art, o happening e a performance), ou lançam mão das novas tecnologias (a fotografia, a ciber arte, a web art, a video-arte, o cinema 
e-Mosaicos - Revista Multidisciplinar de Ensino, Pesquisa, Extensão e Cultura do Instituto de Aplicação Fernando Rodrigues da Silveira (CAp-UERJ) ANO 1 - V. 1 - N. 1 - JUNHO 2012 - ISSN: 2316-9303

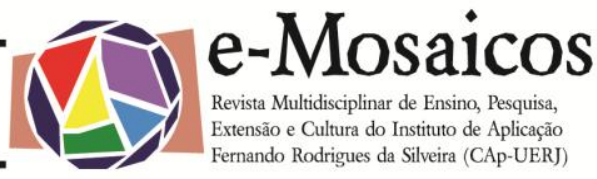

de animação, etc).

A fotografia contemporânea ultrapassa o uso do papel fotográfico, mas vem associada a outros materiais e suportes, e é produzida a partir de variadas técnicas de intervenção, como o uso de diferentes qualidades de filtros. A instalação tem como principal característica a relação com o espaço onde é montada, podendo ter dimensão variada e usar o tipo de material que for necessário para aplicar o conceito que se deseja. Algumas vezes ela utiliza várias linguagens ao mesmo tempo, sendo chamada então de vídeo-instalação, ou instalação multimídia. A intervenção também discute a questão espacial, mas, normalmente ocupa espaços públicos, chamando atenção para monumentos ou locais que não se percebe na correria do dia a dia. A video-arte, ciberarte e web-art utilizam-se de uma linguagem tecnológica para a criação da obra, sem perder-se do objetivo crítico que deve ter.

Este rompimento com as categorias tradicionais de belas artes inclue o espectador como co-participante do processo de apreensão e de criação da obra. A arte contemporânea é um objeto inacabado, e este "corpo transparente" exigirá do espectador mais que uma atitude passiva de observador, mas uma locomoção ou até uma intervenção direta.

O tempo é a quarta dimensão, e foi associado à arte desde o Futurismo, passando pela representação cubista de Picasso e mecânica do Dadaísmo, mas na arte contemporânea manifesta-se na duração do processo de apreciação da obra pelo espectador. Ele pode se manifestar no tempo que o espectador leva para compreender um filme que assiste, ou o tempo que cada observador passará diante de uma obra, ou mesmo longe dela, até apreendê-la e pensá- la. Este tempo está embutido na obra e não pode ser medido, pois depende do observador e suas características intrínsecas. Mas a melhor concepção de quarta dimensão se dá, de fato, quando o espectador pode intervir na obra, a ponto de transformá-la e ser transformado, o que é possível com muitas obras contemporâneas.

Ao longo do tempo, a arte vem sempre acompanhando as mudanças de valores e tecnologias de sua sociedade. A arte contemporânea usa as novas tecnologias como possibilidades de ampliar as fronteiras da linguagem artística. Na era do computador, o artista pode usar os recursos que ele tem para oferecer na criação ou na veiculação da obra, o que não significa que ele não possa continuar usando os meios e recursos artesanais.

A partir da compreensão do conceito de beleza na arte contemporânea, bem como de suas características, os alunos desenvolveram seminários a respeito das várias categorias de linguagens artísticas, trazendo imagens de obras e fazendo sua leitura a partir do suporte teórico que receberam.

Paralelo ao trabalho de fundamentação teórica, desde o inicio deste processo, os alunos estiveram visitando exposições de arte para que pudessem conhecer de perto nosso objeto de estudo e analisar, em loco, os conceitos estudados e o processo de criação do artista. Imagem alguma mostrada em sala de aula substitui o impacto do contato direto do espectador com a obra, ainda mais que a maioria dos alunos nunca tinha entrado em um museu ou galeria.

A primeira exposição visitada foi Picasso: paixão e erotismo, com trabalhos de gravura de vários períodos do artista, realizado em um dos galpões da Estação das Docas 
e-Mosaicos - Revista Multidisciplinar de Ensino, Pesquisa, Extensão e Cultura do Instituto de Aplicação Fernando Rodrigues da Silveira (CAp-UERJ) ANO 1 - V. 1 - N. 1 - JUNHO 2012 - ISSN: 2316-9303

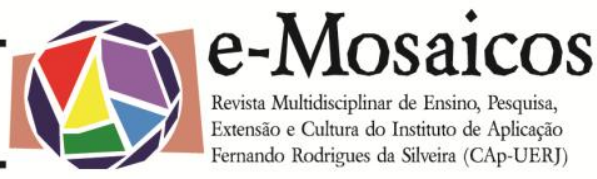

No Salão de Pequenos Formatos UNAMA, os alunos tiveram seu primeiro contato com obras contemporâneas, e pude perceber, em seus rostos, as diversas reações ao deparar-se com objetos, colagens, pinturas, gravuras e instalações. A interrogação diante das obras era uma constante, muitas vezes por não entender o uso de determinado material não convencional, outras por não conseguir perceber o conceito ou discussão desenvolvida pelo artista na obra.

\section{BOTANDO A "MÃO NA MASSA" É QUE SE APRENDE.}

Tendo explorado de diversas maneiras e utilizando a maior quantidade de recursos possíveis, na segunda etapa, a da prática, não queria que os alunos simplesmente fizessem a releitura de uma das obras vistas, ou que construíssem algum objeto "estranho", utilizando um material "diferente". Queria que eles desenvolvessem um projeto elaborado de sua obra, no qual eles tivessem consciência do conceito a ser abordado, da linguagem desejada para trabalhá-lo e da configuração plástica que o trabalho deveria tomar. Este trabalho, da sua concepção à confecção da obra, durou cerca de três meses.

Como na Arte Contemporânea, na maioria das vezes, a ideia sobrepuja o objeto artístico em si, precisávamos partir de uma ideia para pensar a obra, e, neste momento, a inspiração é elemento propulsor da criatividade. Quando falamos em inspiração, nos referimos a coisas que partem dos nossos interesses e nos agradam, e algo muito bom para estimular o interesse dos adolescentes é o cinema. Escolhi cinco filmes do circuito nacional e internacional que fossem atuais e que trouxessem, mesmo que indiretamente, uma critica a questões sociais: Crash: no limite, O Jardineiro Fiel, O Senhor das Armas, $A$ Intérprete e $O$ homem que copiava.

Cada grupo da turma escolheu um filme para assistir e desenvolver uma resenha, onde fosse identificada a problemática contemporânea discutida nele, o que posteriormente foi socializado em forma de debate. A partir dos filmes foram apontadas algumas questões como elemento característico da crise contemporânea: o preconceito, a intolerância, a violência, o tráfico de armas, de drogas e de influência, as diferenças sociais e a ambição desenfreada.

Os grupos precisavam optar por uma temática ou um conjunto delas para aprofundar sua discussão, desenvolvendo uma pesquisa de campo que contextualizasse 0 tema no âmbito da sociedade paraense, através da coleta de reportagens de revistas, jornais e sites locais e da entrevistas com pessoas que vivenciam ou vivenciaram a problemática abordada. $\mathrm{O}$ objetivo é que eles percebessem o quanto estas questões são contemporâneas e podem estar bem próximas de nós, e alguns alunos ficavam surpresos quando percebiam que estes problemas sociais eram mais comuns, em sua comunidade, seu bairro, sua rua e sua família, do que eles podiam imaginar. Eles precisavam ainda escolher um sub-tema, ou um estudo de caso para aprofundar sua ideia, para que ela não fosse tratada de forma generalizada e impessoal.

Escolhida a temática e feita a contextualização, os alunos precisavam estruturar seus projetos, que deveriam conter os seguintes elementos: temática, contextualização, conceito, linguagem artística, materiais necessários e configuração da obra. O conceito seria a discussão específica da qual a obra vai tratar, bem como seu teor de crítica, ironia, drama ou ludicidade. 
Muitos alunos já tinham seus conceitos elaborados, mas não sabiam que linguagem melhor daria forma a eles, enquanto outros tinham escolhido a linguagem artística, mas não tinham domínio de sua técnica, ou estavam em dúvida a respeito dos materiais. Desenvolvemos, então, duas atividades que visavam ampliar o conhecimento das novas linguagens contemporâneas e seus processos de criação: a visita ao Salão Arte Pará e um bate-papo com artistas.

Foi necessária a visita a uma exposição, pois, nessa etapa do trabalho, os alunos precisavam ver de perto obras contemporâneas, para observar as várias possibilidades de técnicas, materiais e discursos conceituais. Não haveria um lugar mais próprio que o Arte Pará 2006, por ser o maior salão de arte contemporânea do norte, com a participação de artistas de todo o Brasil. O salão trouxe um elemento novo nesse ano: um dos núcleos da exposição foi instalado no Mercado do Ver-o-Pêso, em meio às barracas, feirantes e fregueses, levando obras de temática popular a misturarem-se com aquele ambiente, também popular, longe da esfera institucional do museu. Foi interessante, para a vivência dos alunos, conferir obras que discutiam o dia a dia do feirante, do caminhoneiro, abordagens sobre preconceito, consumismo, realidades fictícias e questões da própria arte, tudo isso nas mais variadas linguagens e mídias.

O contato direto com a obra de arte possibilita uma experiência estética mais completa do que a visualização de uma reprodução e quisemos enriquecer mais ainda essa experiência através do conhecimento de quem cria a obra de arte. Realizamos, então, uma conversa com duas artistas plásticas contemporâneas: Danielle Meireles e Keila Sobral, que estiveram apresentando seu relato de experiências artísticas, com- partilhando acerca de processos de criação, poéticas, temáticas e linguagens preferidas (Fig. 01).

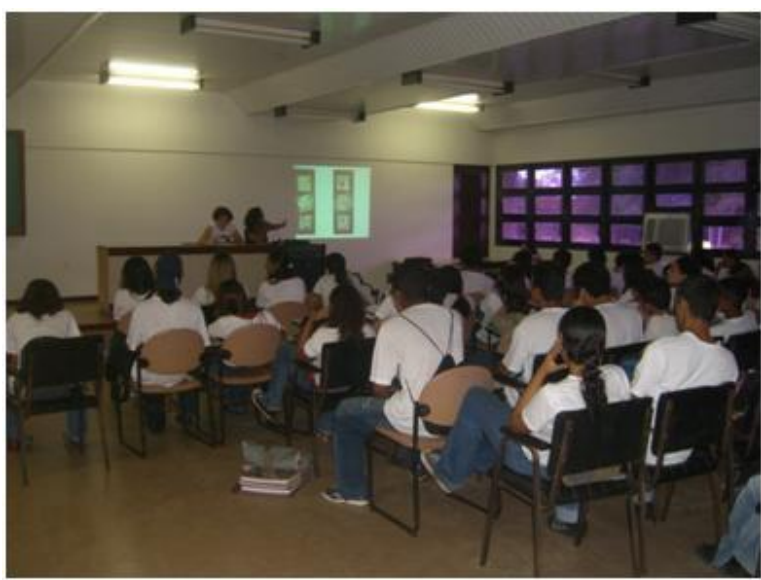

Figura 01: Bate-papo com artistas e as turmas de $1^{\circ}$ Ano do Ensino Médio - NPI.

Danielle Meirelles apresentou seu trabaIho de intervenção, onde, algumas vezes, ela tenta chamar atenção para espaços ou pequenos monumentos dos quais as pessoas não se apercebem na agitação do dia a dia, e em outras, ela trabalha a ironia da busca pela beleza ou questões de sexualidade em banners que são pendurados em prédios públicos, mas que não chegam a passar mais que algumas horas ali.

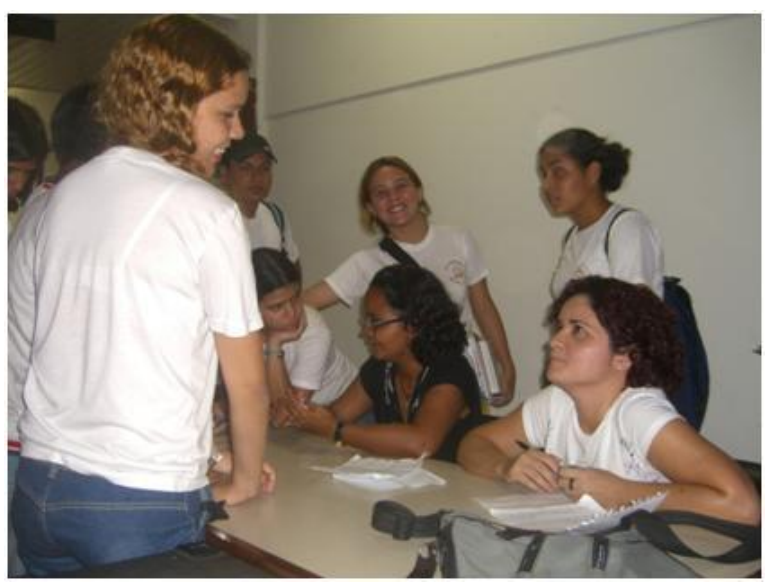

Figura 02: Alunos tirando dúvidas com as artistas Danielle Meireles e Keila Sobral. 
e-Mosaicos - Revista Multidisciplinar de Ensino, Pesquisa, Extensão e Cultura do Instituto de Aplicação Fernando Rodrigues da Silveira (CAp-UERJ) ANO 1 - V. 1 - N. 1 - JUNHO 2012 - ISSN: 2316-9303

Keila Sobral não apresenta preferências por problemáticas sociais, mas tem seu trabalho pautado na discussão do próprio espaço da exposição, elaborando, através de plotagens, linhas gigantes, que formam uma teia e invadem paredes e tetos do lugar escolhido. No momento seguinte, foi aberto o espaço para que os alunos fizessem perguntas às artistas e, ao final da atividade, vários alunos aproximaram-se delas para conversar e pedir sugestões a respeito de seus próprios projetos (Fig.02).

Por várias semanas, os alunos traziam seus projetos, que eram discutidos e aprimorados em sala de aula, mas sem grandes interferências minhas. A última pendência para conclusão do projeto era a escolha do título, uma vez que, para isso, a ideia da obra já devia estar praticamente pronta. 0 título é um elemento interessante, pois pode acentuar o jogo enigmático da obra, com o devido cuidado para não deixá-la hermética demais, ou pode favorecer sua compreensão, mas "sem entregar o tesouro de bandeja".

A culminância do trabalho, realizado com estes alunos, foi a exposição que denominamos de Entranhas da Sociedade, por sintetizar a temática da maioria das obras que tratavam de questões sociais. A exposição ocorreu no dia 12 de janeiro de 2007, uma sexta-feira de atividades normais na escola, o que foi muito importante para que a comunidade escolar pudesse apreciar 0 trabalho realizado.

Como eram seis turmas, cada uma com cerca de seis trabalhos, ao todo tivemos 40 obras, de variadas linguagens, sendo que as técnicas preferidas dos alunos foram o objeto e a instalação, mas colagem, desenho, fotografia e instalação multimídia também foram utilizadas. As obras distribuíram-se por todo o espaço comum da escola, ocu- pando os salões, corredores, banheiros, escadarias e jardins (Fig. 03). Cada lugar de convivência recebeu a intervenção de uma obra e a comunidade da escola obrigatoriamente acabou por apreciá-las, uma vez que elas estavam por todos os lados. A escolha do lugar onde seria exposta a obra foi de fundamental importância e estava prevista no projeto, pois, uma vez que a arte contemporânea dialoga com o espaço, este teria influência para que a obra alcançasse seu objetivo ou não.

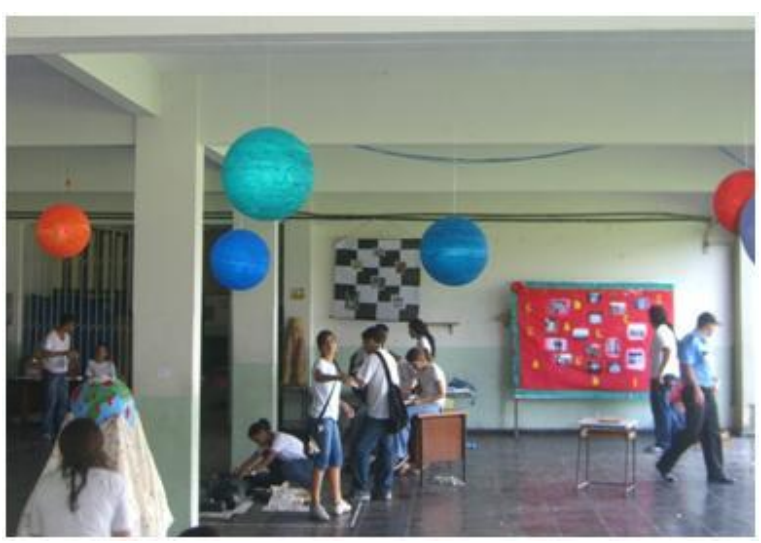

Figura 03: Exposição dos alunos no Salão Cinza/NPI.

A exposição estava marcada para ser realizada durante todo o dia, de nove horas até as dezessete horas. Porém, a montagem dos trabalhos precisava ser no mesmo dia, a partir de sete horas da manhã, para evitar que os trabalhos fossem extraviados ou danificados na noite anterior. Por mais que se planeje o melhor possível para evitar imprevistos, alguns trabalhos, principalmente os de instalação, demoraram bem mais que o esperado para serem concluídos, levando quase toda manhã nesta etapa de montagem. Os alunos precisavam passar o dia inteiro ao lado dos trabalhos, prontos a orientar os espectadores que se aproximassem na compreensão da obra. Para isso, eles se revezaram entre si. 
Uma vez que a maioria dos trabalhos alcançou um nível de amadurecimento muito bom, tive dificuldade em escolher seis entre eles que fossem representativos das linguagens utilizadas, para serem explanados aqui: dois objetos, três instalações e uma fotografia.

A obra $A$ outra face (Fig. 04), dos alunos Tiago, Ismael, Luã e Ingo, foi escolhida por ser um trabalho de fotografia que, ao mesmo templo, é simples e repleto de beleza estética e conceitual. Como a temática escolhida foi a desigualdade social, os alunos tiraram fotografias de alguns pontos de uma comunidade em Belém, chamada Vila da Barca, que ainda possui casas em estilo palafitas: fachadas de casas e crianças com pratos vazios. O suporte utilizado para receber estas fotos reforça ainda mais a estética da simplicidade, que, mesmo assim, consegue ser cheia de beleza pelo conjunto das texturas e cores criadas na obra, a partir do papelão rasgado e do contraste da sua tonalidade com a coloração das imagens e da fita isolante preta, que dá a força rude que emoldura as fotos de maneira irregular. A obra chama o espectador a manuseá-la e adentrar-se neste mundo que é uma "outra face" da nossa sociedade, mas que não está longe de nós.

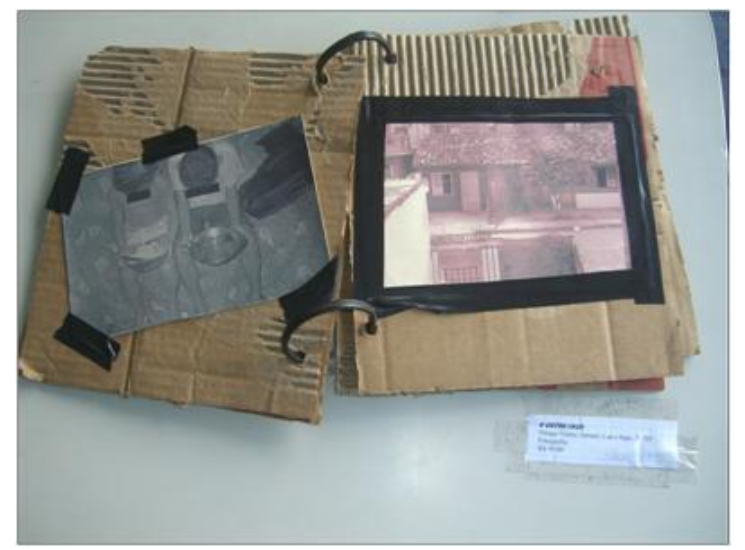

Figura 04: Tiago, Ismael, Luã e Ingo (tur- ma 101), A outra face, objeto.

O Menino do Tráfico que está caído ao chão, objeto feito por Camila, Luana, Magda e Márcia (Fig. 05), não é um simples entregador de drogas ou mesmo um traficante, mas um advogado ou político que usa o sistema de corrupção instalado no Brasil a serviço do tráfico.

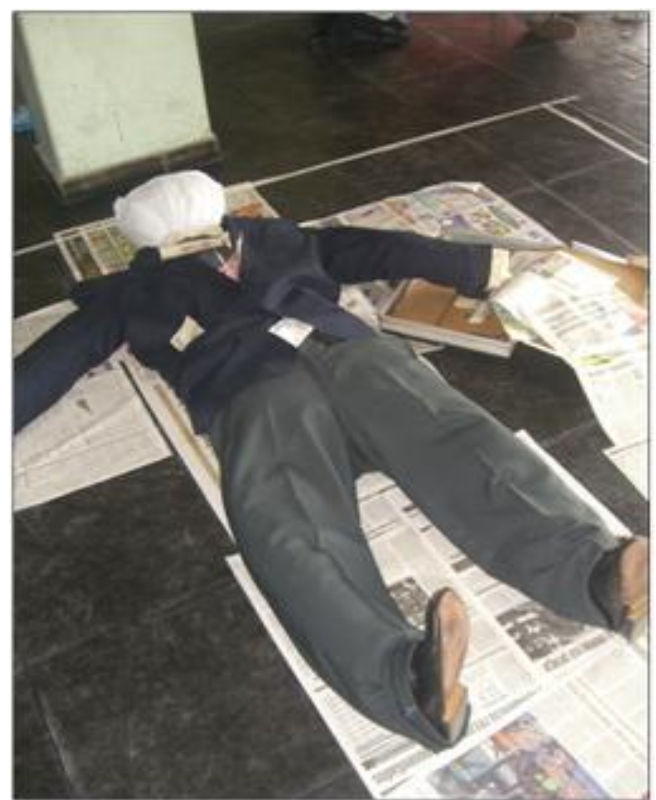

Figura 05: Camila, Luana, Magda e Márcia (Turma 102), Menino do Tráfico. Objeto.

O "boneco" está bem vestido e cheio de dinheiro, e de sua pasta caem reportagens de artistas, advogados e políticos suspeitos de manter relações com traficantes. O trabalho mostra o perigo da relação com 0 tráfico, onde se adquire dinheiro fácil, mas paga-se um preço alto por isso.

Outro trabalho que desenvolveu a temática da desigualdade social foi Favela (Fig. 06), produzido pelos alunos André, Paula, Samantha e Sylnara, que montaram uma barraca de TNT numa escadaria da 
escola que era utilizada. O ambiente criado era simples e possuía alguns poucos objetos como um colchonete e um aparelho de som, que, constantemente, tocava ritmos como brega, funk e forró. Apesar de simples, o lugar era aconchegante e, para que o espectador percebesse a obra como um todo, ele precisava entrar na barraca, onde era

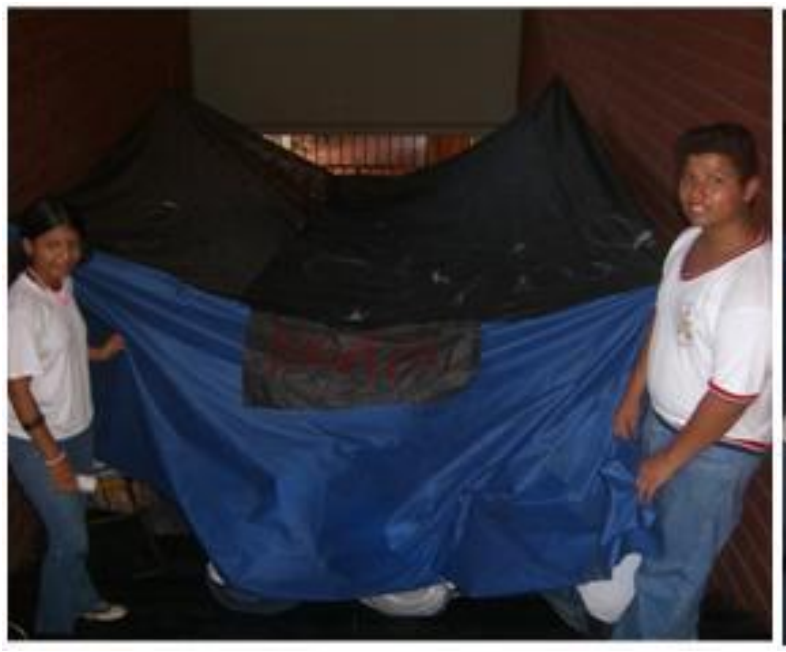

convidado a registrar em um painel seu posicionamento em relação ao preconceito e à desigualdade social. A possibilidade de interação com a obra causou grande interesse por parte do alunado, que a utilizou como ponto de encontro. Os autores registraram quase quinhentas visitas durante a exposição.

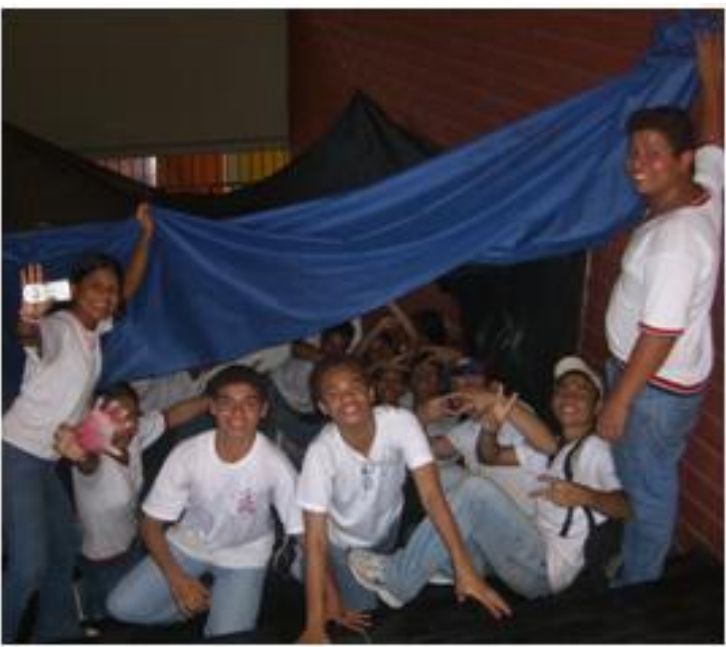

Figura 06: André, Paula, Samantha e Sylnara (Turma 102), Favela, instalação.

Para a elaboração da instalação Valor à vida (Fig. 07), os alunos Arthur, Luís Felipe, Carlos, John e Ian fugiram da minha indicação de filmes e preferiram usar um tema mais existencialista. Basearam-se no filme "Jogos Mortais", que já haviam assistido, e preferiram trabalhar em cima do conceito de que, muitas vezes, as pessoas só dão valor à própria vida quando sentem que ela está ameaçada. Para isso, criaram um espaço completamente fechado, no meio do corredor mais movimentado da escola, utilizando um grande plástico preto que só permitia acesso à parte de dentro através de uma abertura não muito grande.

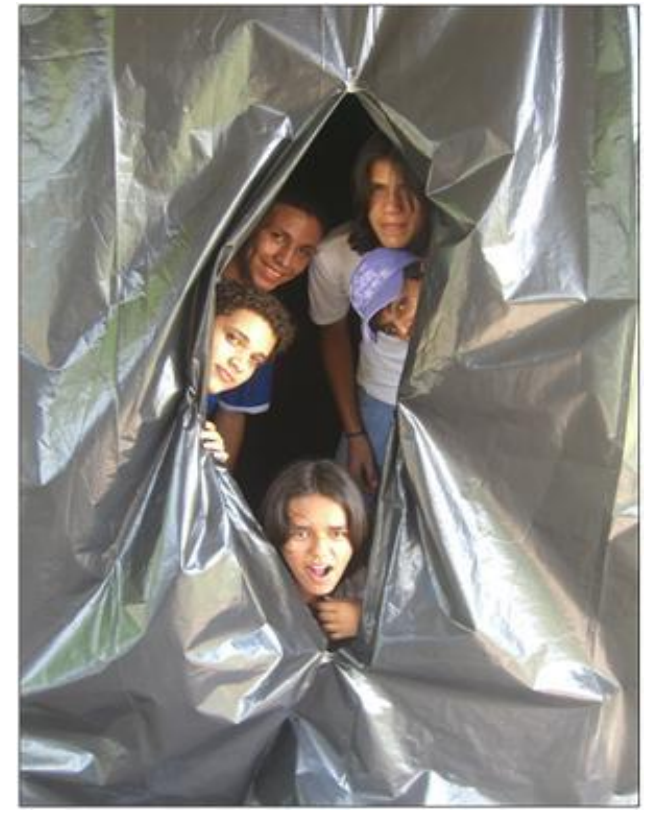

Figura 07: Arthur, Luís Felipe, Carlos, John e Ian (Turma 106) Valor à vida, instalação. 
e-Mosaicos - Revista Multidisciplinar de Ensino, Pesquisa, Extensão e Cultura do Instituto de Aplicação Fernando Rodrigues da Silveira (CAp-UERJ)

ANO 1 - V. 1 - N. 1 - JUNHO 2012 - ISSN: 2316-9303

No espaço escuro de dentro da obra, havia uma música em ritmo trash e uma luz negra que piscava e não permitia que se visse quase nada, mas era possível apenas ler um cartaz na parede onde estava escrito, com tintas especiais, o seguinte texto: "Humanos, seres capazes, destruidores, manipulados e mal influenciados por desejos materiais. Assassinos de suas próprias almas desperdiçam seu tempo em sua vida inteira para descobrir seu pior erro apenas em seus últimos momentos, em seus últimos suspiros." Para os autores, o objetivo é mesmo criar um clima depressivo e opressor, para que o espectador reflita sobre a importância de dar valor a sua própria vida, e aproveitar os momentos agradáveis que ela oferece.

Outro grupo que utilizou uma temática alternativa, mas muito interessante, foi o dos alunos Alex, André, Mauro e Maylson, que brincaram com o conceito da própria arte contemporânea, através do objeto Isso não é licho... isso é arte?! (Fig. 08) Foi utilizada uma caixa de papelão cheia de pedaços de revistas e jornais e objetos velhos, entre eles uma seringa, e foi colocado o título escrito a giz em sua tampa. Mas como uma caixa cheia de lixo pode não ser lixo, e sim arte? Cada pessoa que se aproximava recebia um caderninho de instruções a respeito dos passos que deveria seguir para explorar a obra: procurar uma pequenina chave no meio do lixo para abrir um pequeno cofre que se encontrava ao lado. Quando a pessoa finalmente conseguia achá-la, abria o cofre e dentro dele encontrava outro papel dizendo: se isso é lixo, o que é o resto? Diante da indagação feita, o espectador era convidado refletir sobre ela e registrar em uma folha sua percepção sobre a obra e seu significado.

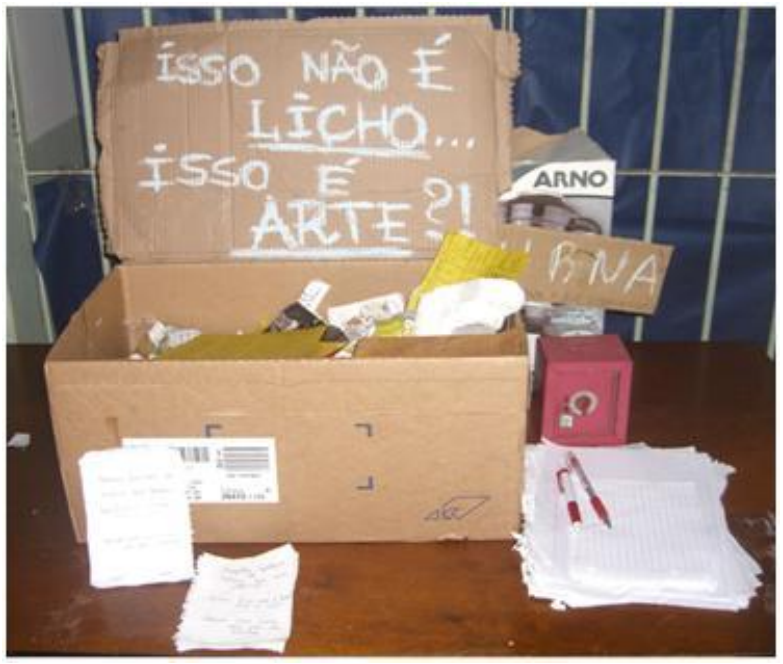

Figura 08: Alex, André, Mauro e Maylson (Turma 105) Isso não é licho... Isso é Arte?!, objeto.

No registro deixado pelos espectadores, foram encontradas as mais variadas interpretações sobre o que viria a ser o lixo representado ali: leituras ecológicas, sociológicas, existencialistas, contra as drogas e a favor da vida, e, principalmente, questionando os padrões tradicionais de beleza em arte. Sobre esta última questão, encontramos um depoimento que diz que "a ideia que temos de lixo é muito errada, pois nem tudo é o que parece ser. A arte é algo livre e subjetivo e a partir desta obra podemos ter uma visão mais ampla sobre ela."

Se percebemos uma visão mais aberta do espectador em relação à arte contemporânea, neste outro depoimento verificamos que alguns ainda a vêem como algo totalmente estranho à sua compreensão: "com certeza esta obra é uma perda de tempo! Isso estraga a beleza de qualquer um, mas, se isso é arte..." Acredito que a obra, no geral, conseguiu trabalhar a ideia de que a beleza na arte contemporânea está no seu conceito e não na sua aparência. Através dos depoimentos dados a este trabalho, 
pudemos ter um retorno, não só a respeito desta obra, mas da exposição de maneira geral.

A última obra que apresentaremos é a instalação Tempos Corrompidos (Fig. 09), das alunas Larissa e Naíra, que foi montada em um banheiro da escola, para criar um clima sombrio e claustrofóbico. As janelas e as portas dos sanitários foram cobertas de TNT preto, para isolar a ideia de banheiro e criar uma penumbra, e foram espalhadas velas brancas e vermelhas pelo chão e pelas bancadas. No percurso de quem entrava para apreciar a obra, se percebia logo o clima carregado, proporcionado pelo cheiro e a iluminação de velas, e o título do trabaIho, pichado em letras grandes na parede de entrada. Ao virar-se para dentro do espaço, o choque: As paredes pichadas de vermelho com símbolos, desenhos infantis, a frase "Vamos brincar?" em letras grandes, e ao centro, uma boneca pendurada pelo pescoço com manchas de tinta, representando sangue.

A trilha sonora do trabalho tem dois momentos distintos, começando com sons de caixinha de música, misturados a cantigas de roda, que aos poucos vai sendo modulada para um rock progressivo. A leitura que se tem é de um momento de infância que é interrompido pela violência infantil, mas existem ainda alguns símbolos que não conseguimos identificar e que talvez sejam importantes para a compreensão da obra.
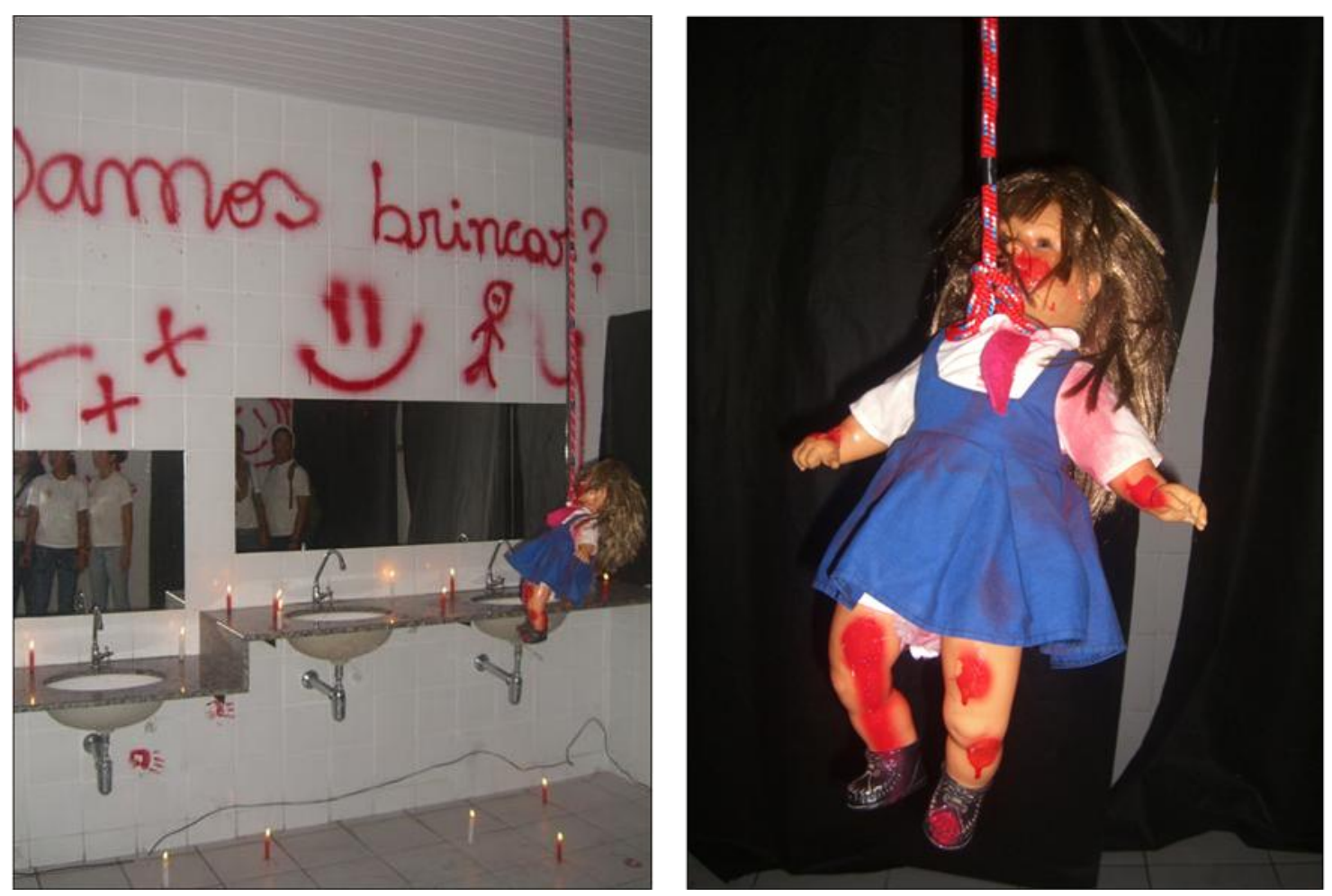

Figura 09: Larissa e Naíra e (Turma 105), Tempos corrompidos, Instalação. 
e-Mosaicos - Revista Multidisciplinar de Ensino, Pesquisa, Extensão e Cultura do Instituto de Aplicação Fernando Rodrigues da Silveira (CAp-UERJ) ANO 1 - V. 1 - N. 1 - JUNHO 2012 - ISSN: 2316-9303

As autoras esclarecem que essa criação fazia referência ao caso dos meninos emasculados de Altamira, caso que tomou repercussão nacional, onde, entre 1989 e 1993, crianças foram encontradas mortas e, segundo as investigações, os crimes foram motivados por rituais de magia negra. Isso explica os símbolos desenhados nas paredes que lembravam inscrições de rituais satânicos, assim como as velas vermelhas espaIhadas pelo ambiente. De acordo com a aluna Larissa Salgado, é abordado "não só esse tipo de violência, mas também a violência psicológica, das crianças que ficam sozinhas em casa enquanto os pais saem para trabaIhar". ${ }^{1}$

Essa obra em especial causou grande impacto e promoveu diversas reações: alguns saíram de lá horrorizados com o realismo com que foi tratado o tema e outros preocupados e indignados com esta realidade da violência infantil, que é mais comum do que se imagina.

Foi bom ver a empolgação dos alunos na confecção dos trabalhos e na execução da exposição, pois aquele era o espaço onde eles iriam ser valorizados e reconhecidos. Afinal, a escola viveu um dia de festa, por causa da movimentação em torno dos trabalhos. Para acentuar o estímulo à participação, atribuímos uma premiação simbólica ao melhor trabalho, que seria escolhido por uma comissão julgadora composta por dois professores de arte e um de sociologia, que deveriam tomar como base os critérios de melhor elaboração de conceito e melhor solução plástica.

\footnotetext{
${ }^{1}$ Baseado na reportagem de cobertura da exposição Entranhas da Sociedade, feita pela jornalista Luciane Fiúza de Mello e divulgada no Blog Luciane Fiuza de Mello... ou simplesmente Lu.
}

\section{FINAL DE FESTA, SALDO POSITIVO.}

Fizemos uma atividade final, onde foi pedido aos alunos que avaliassem o processo vivenciado por eles durante o ano letivo em questão, no qual eles iriam compará-lo a uma viagem feita pelo mundo da arte contemporânea. Eles precisavam abordar 0 roteiro percorrido, os colegas de grupo como companheiros de viagem e a professora como guia turística, refletindo sobre onde se chegou ao final dessa viagem, ou seja, o que puderam aprender.

Sobre a percepção do conceito e da abrangência da arte contemporânea, um dos grupos relatou:

"Passado o primeiro choque, descobrimos que a arte pode ter muito a ver com 0 nosso cotidiano. Aprendemos que podemos encontrar a arte nos mais diversos lugares, sob os mais diversos campos da ciência, como física, matemática, história e outros." (Bruno, Jéssica, Uriel e Walciane, Turma 105).

O grupo de alunos Alexandre, Dyenne, Laíde e Mário, da turma 105, abordou os resultados positivos do trabalho desenvolvido: "Chegamos ao fim do ano letivo cheios de ideias novas, de cultura e de conhecimento. Aprendemos a trabalhar em equipe, analisar uma obra antes de falar qualquer coisa e a criar."

Encher-se da arte e, de repente, descobrir que de aluno virou artista, foi o depoimento das alunas Camila, Luana, Magda e Márcia, da turma 102: "Chegamos ao 'mundo novo' da arte contemporânea, que até então nós desconhecíamos, e aí viramos artistas com a obra 'Meninos do Tráfico'. Já sabemos que a arte é tudo e aprendemos tudo para encher nossas mentes de arte."

As alunas Larissa e Naíra, da turma 105, falaram sobre a dificuldade de passar 
pelo processo criativo, mas, acima de tudo, o gosto de conseguir materializar uma ideia através de uma produção artística. Elas detalharam:

"Pudemos sentir na pele o quanto o artista contemporâneo 'sofre' até chegar ao ponto final de sua obra e o quanto é satisfatório o gosto da vitória, a vitória que alcançamos todos juntos e com um único propósito: fazer o espectador ver, ouvir e sentir a arte, mesmo que seja por apenas alguns minutos, com certeza, inesquecíveis para ambas as partes,"

Descobrir o prazer de ver um observador deparar-se diante de sua obra sem palavras, ou perceber que, ao final, ele conseguiu alcançar a ideia que o artista elaborou, para este é indescritível. Estes alunos puderam ter esta experiência ao fazer o monitoramento da exposição.

Esta exposição é um exemplo de que, quando damos os estímulos e suportes certos, podemos esperar o melhor da criatividade e do empenho de nossos alunos. 0 mais importante foi eles perceberem que a Arte Contemporânea não é "bicho de sete cabeças" e que ela pode ser muito interessante, por mostrar questões do nosso dia-adia.

O objetivo traçado foi alcançado, pois os alunos elaboraram os trabalhos, a partir de uma visão crítica da sociedade e do homem contemporâneo, ou seja, foram capazes de produzir um conceito relevante $\mathrm{e}$ materializá-lo a partir do manuseio de materiais do cotidiano, antes sem valor artístico algum, mas aos quais foi atribuída uma nova ideia, tirando-os da categoria de objetos comuns e transformando-os em arte. Minha maior satisfação foi vê-los orgulhosos em ter suas produções expostas e reconhecidas pela comunidade escolar na qual convivem.

Isto prova que compreenderam o que é arte contemporânea: uma arte que não trata só de coisas agradáveis ou belas, do ponto de vista da estética tradicional, nem preocupa-se apenas com a aparência exterior, mas esquadrinha todos meandros da vida do homem, e é cheia de mistérios e enigmas, onde reside sua verdadeira beleza.

\section{REFERÊNCIAS BIBLIOGRÁFICAS}

BARBOSA, Ana Mãe. Tópicos Utópicos. Belo Horizonte : C/ Arte, 1998.

BARCO, Luiz. O Belo, Série em DVD Arte e Matemática, Vol. 04 - São Paulo : Cultura Marcas, 2005.

COSTA, Cristina. Questões de Arte: a natureza o Belo, da percepção e do prazer estético. São Paulo: Moderna, 1999.

FRANCASTEL, Pierre. Pintura e sociedade. São Paulo : Martins Fontes, 1990.

LANIER, Vincent. Devolvendo arte à arteeducação. In BARBOSA, Ana Mãe (org). Arte-educação: leitura no subsolo. - São Paulo: Cortez, 1997.

OLIVEIRA, Jô e GARCEZ, Lucilia. Explicando a arte: uma iniciação para entender $e$ apreciar as artes visuais. - Rio de Janeiro: Ediouro, 2002.

CORREA, Ayrton Dutra. Ensino de Arte: múltiplos olhares. - Ijuí: Unijuí, 2004.

Secretaria de Educação Média e Tecnologia. Parâmetros curriculares nacionais: ensinomédio / Ministério da Educação, Secretaria de Educação Média e Tecnológica. - Brasília: MEC; SEMTEC, 2002. 
MELLO, Luciane Fiúza de. Entranhas da Sociedade. Blog Luciane Fiuza de Mello... ou Simplesmente Lu. http://simplesmentelu.blogs.sapo.pt/arquivo /2007_01.html\#1059876

THITLEWOOD, David. Estudos críticos: o museu de arte contemporânea e a relevância social. In BARBOSA, Ana Mãe (org). Arte-educação: leitura no subsolo. - São Paulo: Cortez, 1997.

${ }^{1}$ juniasoi@hotmail.com - Mestre em Artes Visuais pela Universidade Federal do Rio de Janeiro (2003). Atualmente é professora da Universidade Federal do Pará, ministrando a disciplina Arte na Educação Básica e História da Arte e Arte Educação no Ensino Superior (PARFOR). Tem experiência na área de Artes, com ênfase em História e Teoria da Arte. Tem projeto de pesquisa em Educação Visual e relações etno-raciais. 